\title{
El “NEODUAlisMo" DE LA POLÍTICA PERUANA
}

\author{
"Neo-dualism"in Peruvian Politics
}

\author{
MARTÍN TANAKA \\ Instituto de Estudios Peruanos
}

\section{SOFÍA VERA}

Instituto de Estudios Peruanos

\begin{abstract}
RESUMEN
El 2007 en el Perú se caracterizó por una suerte de "neodualismo". De un lado, tenemos una parte del país, más urbana, moderna y costeña, relativamente optimista respecto al futuro, que se beneficia del crecimiento de la economía y, del otro, tenemos un país más rural, serrano y amazónico, en el que los beneficios del crecimiento no se perciben, donde los niveles de pobreza se mantienen altos, en el que la legitimidad de las instituciones políticas se mantienen baja. El crecimiento económico ha aumentado la desigualdad y ha revelado los límites institucionales del Estado para gestionar eficientemente los recursos disponibles. Esto ha generado tensiones y frustraciones que se expresan en el aumento de los conflictos sociales, así como en la caída en la aprobación a la gestión presidencial. A pesar de esto, el gobierno ratificó su apuesta política por la promoción de la inversión privada, y mostró una relativa pasividad en materia de reformas institucionales y políticas sociales. El gobierno parece confiar en que el crecimiento económico irá paulatinamente reduciendo la conflictividad y el descontento social; los únicos que podrían atentar contra este esquema son los "los perros del hortelano", quienes traban la inversión privada.
\end{abstract}

Palabras clave: Perú, democracia, Estado, conflictos, Congreso.

\begin{abstract}
2007 in Peru was characterized by a type of "neo-dualism". On the one hand, there is a part of the country that is more urban, modern, and coastal, which is relatively optimistic about the future, that is involved in the expansion of the economy. On the other hand, we have another part of the country that is more rural, in the highlands, in the amazonic forest, where the benefits of economic growth are not perceptible, where poverty levels remain high, and where the legitimacy of political institutions remain low. Economic growth has increased this inequality and has revealed the institutional limitations of the State to adequately manage existing resources. This has created social tensions, that are expressed in increasing social conflict, and in the decline of the levels of support to President Garcia's administration. Despite all this, the current administration has ratified its policy of promotion to private investment, and has overlooked institutional reforms and social policies. This administration seems to believe that economic growth by itself will gradually reduce social unrest; the only ones that could disrupt this policy are those who oppose private investment for ideological reasons.
\end{abstract}

Key words: Peru, democracy, State, conflicts, Congress. 


\section{TEMAS SALIENTES EN LA REALIDAD NACIONAL Y SU IMPACTO POLÍTICO}

\section{Coyuntura económica}

Los auspiciosos indicadores macroeconómicos parecen haber encandilado a las autoridades políticas, desplazando la preocupación por los temas sociales en la que se insistió tanto el 2006. El crecimiento del PBI en 2007 llegó al 8,3\%, la tasa más alta de los últimos trece años, y a diciembre de 2007 alcanzó 78 meses de crecimiento ininterrumpido. Sin embargo, es importante recordar que se trata de un crecimiento que tiene grandes variaciones regionales. Según datos de la Encuesta Nacional de Hogares, entre 2004 y 2006 la variación del gasto per cápita promedio mensual por regiones muestra que, de las siete regiones con mayor crecimiento, todas por encima del $40 \%$, seis se ubican en la costa del país; de las diez primeras, ocho son de la costa (Lima, 114,3\%, Madre de Dios, 104\%; Moquegua, 79,2\%; La Libertad, 46,8\%, Arequipa, 44,2\%, Callao, 43,6\%; Tumbes, 40,1\%; Junín, 37,2\%; Tacna, 35,9\%, y Piura, 34,9\%). En el otro extremo, encontramos cinco regiones en las que el crecimiento fue negativo, todas ellas ubicadas en la sierra y en el oriente del país (Ayacucho, $-31,9 \%$, Ucayali, $-10,8 \%$, Apurímac, $-8,1 \%$, Pasco, $-2,8 \%$, y Huancavelica, $-0,3 \%$ ); y de las diez regiones con menor crecimiento, ocho son de la sierra y del oriente. Este dualismo se expresa también en datos como el siguiente: según el Informe Global de Competitividad 2007-2008 del Foro Económico Mundial, ${ }^{1}$ mientras que Perú ocupa el segundo lugar, después de Chile, en cuanto a la "sofisticación del mercado financiero" en el ámbito de los países latinoamericanos, al mismo tiempo ocupa el antepenúltimo puesto (antes de Guatemala y Honduras) en lo referente a los niveles de salud y educación primaria.

Uno de los logros más saltantes del gobierno en materia económica fue la firma de un Tratado de Libre Comercio (TLC) con Estados Unidos. Las negociaciones, iniciadas en el gobierno anterior, rindieron frutos a finales de año; el 14 de diciembre se dieron cita en Washington D.C. Alan García y George Bush para promulgar la Ley de Implementación del TLC. Con la firma de este tratado se abren un conjunto de expectativas sociales cuya satisfacción podría ser decisiva para el devenir político de los próximos años. Existe preocupación en muchos sectores porque el crecimiento estimulado por la firma del TLC podría no solamente acentuar las diferencias sociales, sino afectar en forma negativa, a los sectores actualmente más vulnerables y en situación de precariedad.

\section{Coyuntura social}

Lo más importante que se debe resaltar en esta área es que el crecimiento económico no ha llevado a reducir la conflictividad o el descontento social; por el contrario, parece haber aumentado la desigualdad, y al mismo tiempo ha revelado con elocuencia los límites institucionales del Estado para gestionar eficientemente los recursos disponibles. De este modo, a pesar de que 2007 registró un alto nivel de crecimiento del PBI, también aumentaron los conflictos sociales. Según la Defensoría del Pueblo, en diciembre 2007 
se registraron 97 conflictos sociales en todo el país, 51 en estado latente y 28 activos. Si analizamos estos últimos, registramos claramente una tendencia creciente; a inicios de año hubo 14 conflictos activos.

Gráfico 1: Evolución de conflictos sociales activos (enero 2007-noviembre 2007).

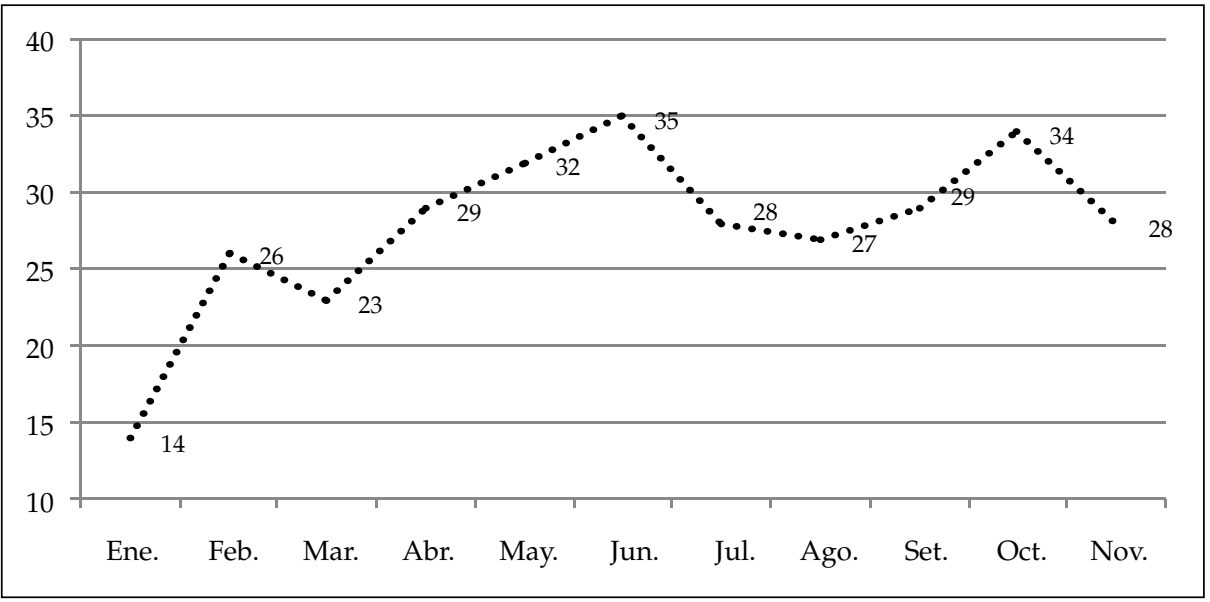

Fuente: Reportes de Conflictos Sociales. Defensoría del Pueblo.

Si analizamos qué tipo de conflictos se produjeron, tomando como referencia el mes de diciembre de 2007, encontramos un $47 \%$ de naturaleza socioambiental (conflictos entre comunidades y empresas mineras por temas de contaminación), y un $27 \%$ en donde se cuestiona de diversos modos a autoridades municipales (acusaciones de corrupción y malos manejos presupuestales). Los problemas socioambientales han aumentado al ritmo del crecimiento de la inversión minera en el país, estimulada por los altos precios de los metales en el mercado internacional. El problema es que la inversión minera sólo recientemente parece estar tomando en serio su responsabilidad social corporativa, y que el Estado carece de una capacidad de regulación y control que permita fiscalizar y sancionar malas prácticas empresariales. Por esta razón, cuando se presentan problemas de contaminación ambiental, las comunidades circundantes a las explotaciones mineras sienten que no tienen medios institucionales para canalizar sus demandas, por lo que recurren a diversas formas de protesta. De otro lado, el cuestionamiento a las autoridades locales se entiende en el marco del proceso de descentralización iniciado en 2001, que les da mayor centralidad política, así como por el aumento de los recursos disponibles para ellos, consecuencia del crecimiento económico: así, tenemos que el presupuesto público de apertura en los gobiernos locales pasó de 1.683 millones de soles en 2002 a 4.294 en 2006. ${ }^{2}$ Más recursos, en un contexto de debilidad institucional y fragmentación política, están creando también más conflictos que antes. 
Ahora bien, a pesar de este aumento en los conflictos, esto no necesariamente implicó un grave desafío para el gobierno. En la gran mayoría de casos estamos ante conflictos aislados con sus propios actores, discursos y dinámicas, sin articulaciones mayores. El gobierno ha enfrentado los conflictos de manera reactiva, con soluciones particulares y respuestas ad-hoc, sin tener propiamente estrategias para enfrentar los problemas de fondo que subyacen a las protestas; no hubo avances significativos en materia de regulación ambiental, tampoco en reformas institucionales respecto al funcionamiento de los gobiernos locales, o los mecanismos de elección de sus autoridades políticas. En medio de este panorama general, es importante mencionar, sin embargo, dos momentos importantes de conflictividad que sí pusieron contra las cuerdas al gobierno por un periodo. Uno de ellos fueron los meses de junio y julio, en los que el Sindicato Único de Trabajadores de la Educación Peruana (SUTEP) se movilizó en contra de la aprobación de la Ley de Carrera Magisterial y un programa de evaluación de los maestros que el gobierno estaba impulsando. La red de maestros afiliados al SUTEP cubre todo el territorio nacional y fue capaz de articular una protesta nacional contra el gobierno, a la que se sumaron otros gremios y actores regionales para reivindicar sus propios reclamos. El gobierno se vio obligado incluso a movilizar a las fuerzas armadas para respaldar las acciones de la policía. Luego de varias semanas de protestas, las negociaciones entre el Ministerio de Educación y el sindicato terminaron en el levantamiento de la huelga. Sin embargo, este foco de conflicto se mantiene latente, en tanto el gobierno continúa impulsando diversas reformas en el sector que son resistidas por el sindicato de maestros.

Otro de los focos de conflictividad que ha enfrentado el gobierno, y que resulta muy preocupante, es el del enfrentamiento con las fuerzas del narcotráfico. Los cultivos de coca y otros productos destinados a la producción de drogas han aumentado en los últimos años, lo que ha generado reiterados enfrentamientos entre las fuerzas del orden y grupos armados financiados por el narcotráfico, entre los cuales se encuentran también algunos grupos vinculados a Sendero Luminoso. Así, por ejemplo, en el mes de noviembre hubo tres ataques directos a las fuerzas policiales; un ataque a la comisaría de Ocobamba, y ataques a vehículos policiales en Tayacaja y Luricocha, localidades del sur del país, siendo el valle del río Apurímac y Ene, en la parte sur de la selva peruana, uno de los puntos más problemáticos.

\section{Coyuntura política}

En este marco económico y social, la aprobación a la gestión del presidente García cayó sistemáticamente a lo largo del año (salvo un ligero repunte en septiembre, consecuencia de la rápida reacción inicial del gobierno frente al terremoto ocurrido el 15 de agosto en la ciudad costera de Pisco, unos 250 kilómetros al sur de Lima, que causó 595 muertes). La aprobación al inicio de su gobierno fue de $63 \%$, a inicios de año cerca al $50 \%$, y a finales de 2007 había caído hasta un 33\%. 
Gráfico 2: Evolución de la aprobación presidencial (mayo-dic. 2007).

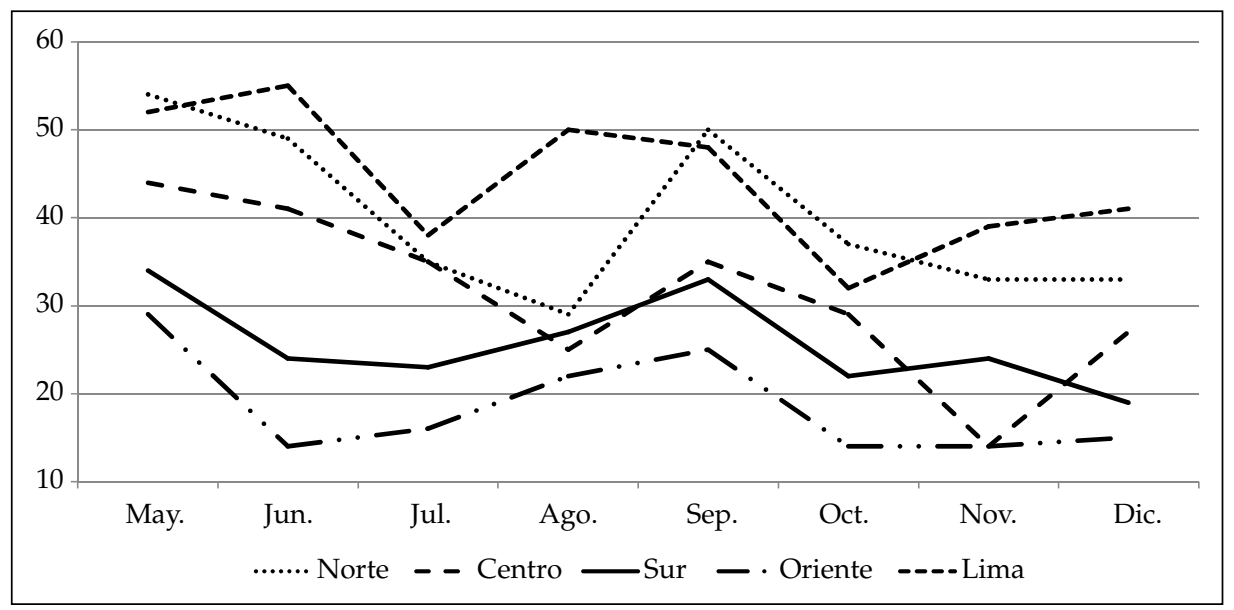

Fuente: Informes de Opinión Data, mayo 2007-diciembre 2007. IPSOS-APOYO.

El análisis desagregado de este dato nacional resulta muy revelador. Como puede verse en el Gráfico 2, es claro que el apoyo al presidente se encuentra en Lima y en la región norte, mientras que es significativamente menor al promedio en el sur y el oriente, lo que dibuja gruesamente el mapa de los resultados electorales de 2006. En términos socioeconómicos, los sectores más altos apoyan en mayor medida al gobierno que los sectores bajos; así por ejemplo, según datos de diciembre de 2007, mientras que en el nivel socioeconómico "A/B" se aprobaba al presidente en un $50 \%$, en el nivel " $\mathrm{C} / \mathrm{D}$ " la aprobación a su gestión llegó apenas al $24 \%$.

Pese a lo adverso de las encuestas de opinión, el gobierno de García se ha mantenido muy estable, a diferencia del anterior, en el que la caída de la aprobación al presidente Toledo alimentaba especulaciones sobre una posible destitución por parte del Congreso. La clave de la estabilidad de García se encuentra en la fragmentación de la protesta social, como ya hemos visto, en la debilidad de la oposición política, y en la fortaleza de la coalición que sustenta su gobierno. Como veremos más adelante, la oposición política en el Congreso está muy fragmentada, lo que le ha permitido al gobierno manejar el Poder Legislativo, pese a no contar con mayoría en lo formal. Por lo general el gobierno cuenta con el apoyo de la bancada fujimorista y de una buena parte de la Unión por el Perú (UPP). En diversos momentos de tensión, en los que el gobierno ha necesitado de mayoría parlamentaria, ha conseguido ésta negociando con los congresistas la realización de ciertas obras públicas en sus circunscripciones electorales.

Muchos pensaron que la lealtad de los votos fujimoristas en el Congreso estarían en cuestión con la extradición del ex presidente Fujimori, ocurrida en septiembre, y el inicio de sus juicios, poco tiempo después, con lo que el gobierno se pondría en aprietos. Este es uno de los pocos casos en el mundo en el que se aprobó la extradición de un ex presidente a su país de origen para ser juzgado, siendo los delitos más graves aquellos que lo vinculan con crímenes de lesa humanidad y de violación a los derechos humanos. En 
la medida en que se evaluaba que el apoyo del fujimorismo al gobierno se daba a cambio de que el gobierno entorpeciera el proceso de extradición, se creyó que el enjuiciamiento al ex presidente marcaría una ruptura de relaciones entre el fujimorismo y el gobierno, lo que comprometería el control del Congreso por parte de éste. Sin embargo, el histórico enjuiciamiento a Alberto Fujimori ha transcurrido con total normalidad, y los alineamientos políticos no han sufrido cambios sustanciales.

Pero la base de sostenimiento más firme del gobierno se encuentra en el respaldo de los poderes de facto, que involucran a los grandes capitales, la iglesia católica y las Fuerzas Armadas; García ha optado por un modelo de gobernabilidad conservadora, que ha tenido como ejes centrales el privilegiar las demandas de orden y autoridad, y el asegurar el crecimiento económico mediante una política "amigable" con los grandes capitales. En el plano táctico, dada la inexistencia de oposición política, el reto fue contener la protesta social, según el gobierno "azuzada" por "agitadores" con intereses políticos, así como por activistas de Organismos No Gubernamentales (ONGs). Para ello se lanzaron algunas iniciativas, como la aprobación de una ley que abría la posibilidad para ejercer presión política y administrativa a las ONGs a través de la Agencia Peruana de Cooperación Internacional (APCI) en diciembre de $2006,{ }^{3}$ o la promulgación de una serie de decretos legislativos que aumentaban las sanciones y los tipos penales para quienes participen en protestas no autorizadas y violentas, en el mes de julio. Sin embargo, los cuestionamientos a estas normas hicieron que el gobierno no haya seguido propiamente un camino represivo, y por lo general se ha impuesto el recurso de la negociación y el diálogo, en donde destaca el liderazgo del Presidente de Consejo de Ministros, Jorge del Castillo. Además, el Tribunal Constitucional declaró inconstitucional en el mes de septiembre varios de los artículos de la ley APCI. ${ }^{4}$ La pregunta es qué rumbo seguirá el gobierno si es que Del Castillo es sustituido, porque dentro del partido de gobierno éste representa el ala más moderada y dialogante, habiendo otros sectores mucho más proclives a la confrontación con los opositores.

\section{Coyuntura internacional}

En el ámbito internacional lo más importante ha sido la firma del Tratado de Libre Comercio (TLC) con los Estados Unidos, al que ya hemos hecho referencia, así como los avances en la preparación de la cumbre de la APEC (Foro de Cooperación Económica Asia-Pacífico), y del Encuentro de Jefes de Estado de la Unión Europea y Latinoamérica, que se realizarán en 2008.

En el ámbito regional, hubo algunos incidentes diplomáticos con los gobiernos chileno y venezolano. En el primer caso, la iniciativa del gobierno peruano de presentar el tema

3 Ley que determinaba que las organizaciones privadas que recibieran fondos de cooperación internacional fueran controladas mediante procedimientos administrativos por la Agencia Peruana de Cooperación Internacional (APCI).

4 Los artículos 3, 4, 5 y 9, que afectaban la autonomía de las ONGs y permitían una intervención gubernamental sobre sus actividades. Se aclaró así que sólo estarán bajo el régimen de la APCI aquellas instituciones cuyos fondos de cooperación internacional hayan sido gestionados por el Estado. 
del diferendo de la frontera marítima con Chile ante la Corte Internacional de La Haya (concretada a inicios de 2008), ha enfriado un tanto la relación con el gobierno chileno, que inició en muy buenos términos al comenzar el mandato de García. El gobierno peruano ha trabajando arduamente para acudir a la justicia internacional y resolver lo que desde su posición es un problema de definición de límites marítimos; sin embargo, para Chile la controversia no existe: en la actualidad el área reclamada por Perú está bajo control de Chile, amparada en convenios de pesca y otros acuerdos, que según el Perú no tienen el valor de un tratado de límites.

Con Venezuela, si bien la relación bilateral ha mejorado sustancialmente desde el inicio del gobierno de García, en 2007 se registraron algunos problemas asociados a la presencia en diversas ciudades del país (como Arequipa, Puno, Cusco y Tacna) de las "Casas del ALBA" (Alternativa Bolivariana para Nuestra América). El gobierno peruano expresó su preocupación ante lo que podría ser una forma de injerencia política en asuntos domésticos; la representación diplomática venezolana, por su parte, afirmó que su gobierno no tiene ningún vínculo con las Casas del ALBA, que serían iniciativas ciudadanas privadas. En la actualidad, las actividades de las Casas del ALBA están siendo objeto de escrutinio por parte del gobierno, y en función de ello se tomarán decisiones, si fuera necesario, según voceros del gobierno.

\section{Cambios institucionales}

En contra de lo que se esperaba del nuevo gobierno, dados los resultados de las elecciones de 2006, no se ha avanzado significativamente en cuanto a reformas institucionales. Si bien diversas propuestas de reforma han estado presentes en el debate público, ellas no se han concretado en cambios legislativos concretos. Se ha debatido sobre la necesidad de implementar reformas en el sistema electoral, de modificar la ley de partidos políticos; el establecimiento de un modelo bicameral en el Congreso, la eliminación del voto preferencial para la elección de congresistas, la renovación parcial de los miembros del Congreso, el voto facultativo, la participación obligatoria de la Oficina Nacional de Procesos Electorales (ONPE) en las elecciones internas de los partidos políticos.

La bicameralidad fue intensamente discutida en mayo y finalmente aprobada en la Comisión de Constitución del Congreso. El funcionamiento del Congreso con dos cámaras supondría una separación de funciones; legislativa y fiscalizadora para los diputados, y de revisión y nombramiento de funcionarios públicos para los senadores. La Cámara de Diputados estaría compuesta por 120 miembros elegidos como ahora en circunscripciones departamentales, mientras que la de senadores estaría compuesta por 50 miembros elegidos en una única circunscripción nacional, abandonándose el congreso unicameral de 120 miembros actual. Esta reforma requería una modificación de la Constitución; sin embargo, el proyecto no ha llegado a ser debatido en reunión del pleno del Congreso. En general, no parece haber un buen clima para este tipo de reforma, dado el desprestigio del Poder Legislativo, expresado emblemáticamente en diversos escándalos, por ejemplo, los que involucraron a los congresistas Elsa Canchaya y Walter Menchola, ambos de Unidad Nacional (en ambos casos se trató de la contratación de familiares y allegados a los 
congresistas como asesores, cuando los contratados no contaban con ninguna calificación para ese cargo). Con un gobierno sin voluntad política por sacar adelante estas reformas, y un Congreso muy fragmentado, la discusión de los temas de fondo ha sido aplazada por la atención a temas de coyuntura.

Las reformas institucionales que el gobierno ha impulsado tienen un carácter básicamente administrativo, y pierden de vista una reestructuración integral del aparato estatal, supuesto tema de preocupación al inicio del gobierno. El gobierno dio algunos pasos pero no concretó nada muy significativo, por ejemplo se decretó el reordenamiento de los Organismos Públicos Descentralizados (OPDs), así como la fusión de los distintos programas sociales, buscando simplificar y hacer más eficiente el funcionamiento de las estructuras estatales. Sin embargo, los resultados hasta el momento han sido limitados.

En cuanto al proceso de descentralización, el año empezó con la desactivación del Consejo Nacional de Descentralización (CND), siendo sus competencias transferidas a la Presidencia del Consejo de Ministros (PCM). Este hecho reflejó la negativa del gobierno a seguir un proceso relativamente pautado, con metas y plazos específicos (aunque ciertamente poco realistas), y su preferencia por establecer negociaciones particularistas con los distintos gobiernos regionales. La respuesta de una parte de ellos (18 de 25) fue la creación de la Asamblea de Presidentes Regionales en el mes de marzo, que levantó una agenda descentralista que empezó a ser objeto de negociaciones bilaterales. Sin embargo, los reclamos por mayores recursos y competencias ante el gobierno central han perdido intensidad, en la medida en que el presupuesto de los gobiernos regionales ha ido en aumento, aunque no necesariamente la capacidad de ejecución del gasto, como veremos más adelante.

Finalmente, cabe mencionar que sólo a finales de 2007 el Congreso aprobó una ley fundamental para la reforma del Estado, la Ley Orgánica del Poder Ejecutivo (LOPE). Esta ley es fundamental para completar el marco legal de la descentralización, y adaptar las estructuras del Ejecutivo a los cambios que impone este proceso. La ley detalla las atribuciones exclusivas del gobierno central y establece mecanismos de coordinación con los otros niveles de gobierno.

\section{Poder Ejecutivo}

a) La rotación del gabinete

El gabinete que inició en julio de 2006 se renovó en un 50\% a lo largo de 2007 (de 16 miembros, sólo 8 se mantienen desde el inicio). Seis cambios ocurrieron el 20 de diciembre; los cambios que ocurrieron por presión política se dieron en las carteras del Interior (en febrero) y Agricultura (en mayo). La salida de la ministra del Interior Pilar Mazzetti se produjo en el marco de cuestionamientos al proceso de compra, mediante licitación pública, de vehículos para la Policía, y la del ministro de Agricultura, Juan Salazar, al reconocer el error de firmar un acuerdo con campesinos de la región Cusco según el cual el gobierno se comprometía a estudiar el proponer "el retiro de la hoja de coca de la lista de estupefacientes de la Convención de Viena". 
Pese a los intentos de la oposición en el Congreso, ningún ministro fue censurado. El procedimiento de censura a un ministro requiere de dos pasos. Primero, sacar adelante un pedido de interpelación firmado por al menos el 15\% del número legal de congresistas y conseguir su admisión mediante el voto de un tercio de congresistas hábiles. Segundo, luego de la interpelación, presentar una moción de censura con la firma del $25 \%$ del número legal de congresistas y aprobarla mediante votación por más de la mitad del número legal de congresistas. El Congreso fue muy activo en la fiscalización de los ministros; las interpelaciones y pedidos de censura a algunos ministros han estado presentes reiteradamente en el debate político, aunque sin resultados; sin embargo, debe mencionarse que la renuncia de la ministra Mazzetti ocurrió cuando el Congreso preparaba un pedido de interpelación, que podría haber dado lugar a una censura.

Los pedidos de interpelación que sí prosperaron en el Congreso fueron el del ministro de Salud, César Vallejos, convocado a responder un pliego de preguntas sobre el tema de la compra irregular de alimentos para los damnificados del terremoto de Ica del 15 de agosto. Sin embargo, los promotores de la censura (Unión por el Perú, UPP, y el Partido Nacionalista Peruano, PNP), lograron juntar sólo 35 de los 61 votos necesarios para abrobar una moción de censura. Otra moción de interpelación que prosperó fue la del presidente de Consejo de Ministros Jorge del Castillo, por el irregular nombramiento de un ex ministro del gobierno de Alberto Fujimori, inhabilitado de ejercer funciones públicas por diez años (Alberto Pandolfi) como jefe del Programa de Reducción de la Vulnerabilidad frente al Evento Recurrente de El Niño. A pesar de que Del Castillo acudió voluntariamente al Congreso para explicar de qué manera se dio este nombramiento, se aprobó una moción de interpelación en su contra, con 50 votos. Sin embargo, la oposición no pudo presentar una moción de censura, dado que el nombramiento fue rápidamente anulado.

Otra interpelación ocurrió en octubre, cuando el ministro del Interior, Luis Alva, fue citado a propósito de la nuevamente frustrada adquisición de patrulleros (la misma razón por la cual renunció su antecesora) y la compra sobrevalorada de municiones antimotín para la Policía. Aunque la moción de censura en su contra llegó a presentarse con el apoyo de los congresistas de UPP, PNP y de la AlianzaParlamentaria (AP), ésta no fue aprobada, como veremos más adelante. La permanencia de Alva en el gabinete ministerial era importante para el partido de gobierno, ya que éste es uno de sus principales dirigentes nacionales. Sin embargo, Alva Castro es el ministro con el menor nivel de aprobación a su gestión de todo el gabinete.

\section{b) La dinámica del gabinete}

La proporción de apristas en el gabinete se ha mantenido estable y en un número reducido (seis de 18 miembros). En cuanto al funcionamiento del gabinete, el liderazgo del Presidente de Consejo de Ministros, Jorge del Castillo, se ha visto en ocasiones limitado por obra del propio Presidente de la República. Dentro del gabinete, la presencia de un importante líder partidario como Luis Alva, se pensó inicialmente, podría haber establecido un contrapeso al liderazgo de Del Castillo, pero ello no ocurrió dadas las dificultades que enfrenta Alva en su sector. Recientemente, el nombramiento en diciembre de Antero Flores, un político con juego propio, como Ministro de Defensa podría establecer ese contrapeso en el futuro. 
El funcionamiento del gabinete adoleció de dos problemas básicos en el 2007; de un lado, el haber seguido una lógica básicamente reactiva y cortoplacista, en donde no se perciben agendas sectoriales claras, ni una orientación general reformista. Como hemos señalado, parece existir un sentido común según el cual lo verdaderamente importante es mantener el crecimiento económico, asumiendo posturas favorables a la inversión privada, desatendiéndose relativamente otros asuntos. El otro problema para el gabinete ha sido la reiterada intervención del Presidente de la República con iniciativas no coordinadas adecuadamente con su gabinete, lo que hace que los ministros tengan después que improvisar rápidas respuestas a iniciativas que posteriormente demuestran poca viabilidad, o que entran en conflicto con otras iniciativas e instituciones ya existentes, como veremos. Es importante analizar con más detenimiento la conducción del presidente García.

\section{c) Estilos presidenciales}

Alan García es un presidente con un protagonismo muy fuerte, que suele estar presente en la escena pública de manera permanente, desplazando a sus ministros de Estado, y que suele responder a los cuestionamientos que recibe su gobierno con el lanzamiento de iniciativas audaces y de gran impacto inmediato, pero que se diluyen con el paso del tiempo. Algunos ejemplos de esto son la creación del "Pacto Social" en agosto (busca tender puentes entre el empresariado y los trabajadores para llegar a acuerdos que permitan la mejora de las condiciones laborales), del Fondo para la Reconstrucción del Sur (FORSUR) en septiembre, o de la Oficina Nacional Anticorrupción (ONA) en octubre.

El Pacto Social fue anunciado por el presidente en el discurso a la nación del 28 de julio, cumplido el primer año de gobierno, y presentado como una iniciativa destinada a resolver los problemas del empleo, productividad y salarios. Sin embargo, la improvisación de la medida se dejó ver inmediatamente cuando el presidente de Consejo de Ministros tuvo que designar a un responsable político que diseñara las atribuciones de esta nueva entidad, cuyas funciones se superponían con las del Consejo Nacional del Trabajo y del Acuerdo Nacional. Meses después, los avances del Pacto Social han sido nulos, la iniciativa fue perdiendo fuerza y terminó en el olvido.

El caso del FORSUR es interesante porque no sólo demuestra el desinterés del gobierno por fortalecer institucionalmente el proceso de descentralización del Estado, sino que además reafirma la apuesta política de una alianza con el empresariado. El FORSUR fue creado con el objetivo de "planificar, desarrollar y priorizar los proyectos" de reconstrucción de las ciudades de la región Ica que fueron devastadas por el terremoto del 15 de agosto; y fue iniciativa de la presidencia colocar en la dirección del FORSUR a un conjunto de empresarios, bajo la lógica de que la aplicación de una mentalidad de "empresa privada" haría más eficiente su funcionamiento, y que las tareas de reconstrucción se orientarían a facilitar el despegue económico de la región. Esta propuesta, sin embargo, desplazó relativamente a la autoridad regional, a las autoridades locales y a otros actores de la sociedad civil; a la fecha, el balance es muy negativo, y la supuesta "habilidad ejecutiva" de la dirección del FORSUR no se ha hecho evidente en absoluto. 
Finalmente, en cuanto a la ONA, se trata de una iniciativa que busca responder a la preocupación ciudadana por diversos escándalos de corrupción ocurridos en el gobierno, pero mediante la creación de una institución que tiene competencias superpuestas a la de la Contraloría General de la República, la Procuraduría y el Ministerio Público, entre otros. En la actualidad, la ONA intenta legitimarse como una entidad que coordina y articula las diversas iniciativas contra la corrupción que se dan dentro del Estado.

Ahora bien, este manejo reactivo y cortoplacista de la gestión pública no implica necesariamente que el gobierno carezca de una visión estratégica: ciertamente la tiene, el asunto es que ella pone como protagonista al capital privado, en donde el papel del Estado queda básicamente reducido a no entorpecer la inversión y asegurar "el orden público y la paz social", perdiéndose de vista relativamente sus funciones distributivas o de promoción de sectores menos favorecidos o no articulados a la actual dinámica de crecimiento. Esta manera de ver las cosas fue expresada claramente por el presidente García a través de dos artículos publicados en el diario El Comercio, "El síndrome del perro del hortelano" (28 de octubre) y "Receta para acabar con el perro del hortelano" ( 25 de noviembre) que, como era de esperarse, generaron mucho debate y controversia. ${ }^{5}$

\section{Poder Legislativo}

\section{a) Composición partidaria}

Al iniciar el gobierno aprista, en el Congreso había cinco grupos parlamentarios, con dos agrupaciones preponderantes, la de Unión por el Perú (UPP), en alianza con el Partido Nacionalista Peruano (PNP), y la del partido de gobierno. Al finalizar 2007, encontramos un Congreso que en la práctica, de manera informal, funciona hasta con ocho grupos, haciendo más complicada la negociación parlamentaria. La alianza UPP-PNP se rompió al poco tiempo de iniciar el actual periodo de gobierno; UPP ha sufrido graves disputas internas, expresadas en votaciones divididas en temas importantes; y los demás grupos han sufrido deserciones y actos de indisciplina, con la relativa excepción de las bancadas del APRA y la fujimorista. A pesar de la vigencia de la ley de partidos, de la ley de barrera electoral y de la modificación del reglamento del Congreso para fortalecer el funcionamiento de éste sobre la base de grupos parlamentarios (y no de parlamentarios individuales), reformas implementadas en los últimos años, la fragmentación y escasa cohesión de los grupos políticos no ha podido ser solucionada, lo que sugiere la necesidad de emprender reformas más profundas, como la eliminación del voto preferencial, ${ }^{6}$ por ejemplo.

5 Ver al respecto la página http://delhortelanosuperro.blogspot.com/, donde se recopilan muchas de las reacciones generadas por los artículos.

6 Los electores pueden votar específicamente por dos candidatos dentro de una lista partidaria. Los votos preferenciales reordenarán la lista de candidatos propuesta por el partido político y definirán quiénes ingresan al Congreso. 
Gráfico 3: Composición del Congreso 2006 y 2007.

Congreso 2006

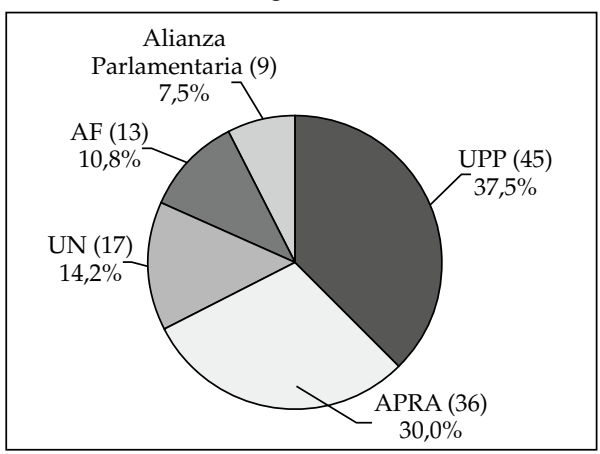

Congreso 2007

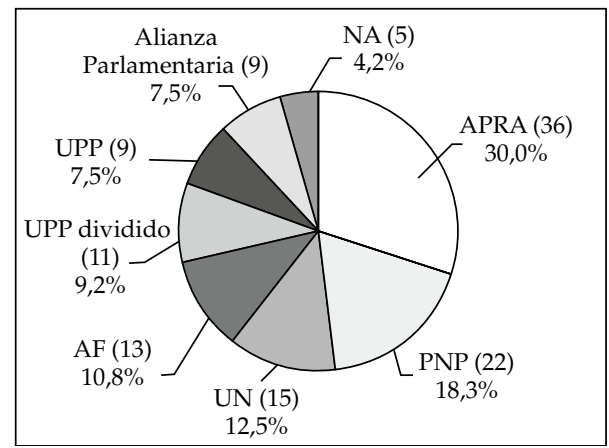

Uno de los momentos en que se hicieron evidentes los problemas de funcionamiento de los partidos en el Congreso ocurrió en la votación para la elección de la nueva Mesa Directiva para el periodo legislativo 2007-2008, en la que compitieron la lista presentada por el partido de gobierno, presidida por Luis González, y la presentada por Unidad Nacional, encabezada por Javier Bedoya. Puede verse que el APRA y la Alianza para el Futuro (fujimoristas) votaron disciplinadamente, y ambos mantienen los mismos parlamentarios que fueron electos. UPP no pudo definir una posición unitaria, y al final diez votaron por González, ocho por Bedoya, uno votó en blanco y otro viciado. El PNP sí votó disciplinadamente. Unidad Nacional colocó 17 parlamentarios en las elecciones, sin embargo en julio de 2007 su candidato, Javier Bedoya, solo obtuvo 12 votos de ese grupo; uno votó por González, uno estaba con licencia, otro suspendido por falta a la ética parlamentaria y dos (miembros del Partido Renovación Nacional, ahora aliado con el gobierno) desertaron de la alianza. La Alianza Parlamentaria, formada por nueve miembros (de tres partidos distintos, unidos para formar un grupo parlamentario), que acordó votar por Bedoya, tuvo un miembro que votó por González, y otro que no asistió a la sesión sin justificación. Finalmente, tenemos cinco congresistas "no agrupados" (NA), que no lograron formar un grupo parlamentario (tres congresistas que abandonaron UPP y dos Unidad Nacional), que votaron por González.

Cuadro 1: Votación Mesa Directiva del Congreso 2007-2008.

\begin{tabular}{lcc}
\hline Partidos & González & Bedoya \\
\hline Apra & 36 & 0 \\
AF & 13 & 0 \\
UPP & 10 & 8 \\
NA & 5 & 0 \\
PNP & 0 & 22 \\
UN & 1 & 12 \\
AP & 1 & 7 \\
Total & 66 & 49 \\
\hline
\end{tabular}


Este tipo de alineamiento político se repitió en otra coyuntura clave, la de la votación en el mes de octubre de la moción de censura al ministro Alva Castro. En esa ocasión se repitieron gruesamente los mismos alineamientos: en contra de la censura votó el APRA (28 votos), y dos de los no agrupados; a favor de la censura votó el PNP de manera disciplinada (22 votos); pero UPP apenas aportó once votos, Unidad Nacional 10, la Alianza Parlamentaria 7 , y un voto de los no agrupados; el fujimorismo se abstuvo (diez votos), con lo cual Alva Castro evitó la censura.

En suma, tenemos que el partido de gobierno, pese a no contar con mayoría, logra construirla ya sea mediante acuerdos políticos específicos (básicamente con Unidad Nacional y la bancada fujimorista), como obteniendo apoyos a cambio de negociaciones particularistas, posibles por la debilidad y escasa disciplina de los grupos parlamentarios (especialmente la UPP), quedando el papel opositor básicamente en las bancadas del PNP y la Alianza Parlamentaria (compuesta por cinco parlamentarios del Frente de Centro (de los cuales cuatro son de Acción Popular y uno de Somos Perú), dos de Perú Posible y dos de Restauración Nacional.

\section{b) Indicadores de producción}

Según los indicadores de gestión de la última legislatura del Congreso, ${ }^{7}$ en la segunda mitad del 2007 (primera legislatura del periodo 2007-2008) se presentaron 547 proyectos de ley, de los cuales 385 fueron iniciativa de los grupos parlamentarios. Entre los partidos que más proyectos de ley presentaron están el APRA (113) y UPP (70). El total de proyectos de ley presentado por la oposición suma 272. En cuanto a la función de control del Congreso, la Comisión de Fiscalización y Contraloría llevó a cabo 15 investigaciones de interés público y extendió 20 invitaciones a ministros y altos funcionarios para brindar información. En total, a las comisiones especiales, a la comisión permanente, al pleno, y a la Presidencia del Congreso, los ministros acudieron 122 veces (ver Cuadro 2).

Por su parte, el Informativo Reflexión Democrática (RF N 119 , del 14 de diciembre de 2007), contabiliza 514 proyectos de ley presentados en la legislatura julio-diciembre 2007, un número menor al registrado en el periodo julio-diciembre 2006 (847). De los proyectos presentados, RF contabiliza 357 del propio Congreso (69\%), 113 del Poder Ejecutivo (22\% del total), y 44 de organismos autónomos. Ahora bien, de los proyectos presentados por el Congreso, apenas un 2,5\% fueron aprobados (9), mientras que ese porcentaje sube a un $34 \%$ cuando se trata de los proyectos del Ejecutivo (38). En cuanto a los organismos autónomos, se aprobó el $7 \%$ de sus propuestas, 3 proyectos. 
Cuadro 2: Indicadores de Gestión del Congreso.

\begin{tabular}{|c|c|c|}
\hline Indicadores de Gestión del Congreso (resumen) & $\begin{array}{c}\text { 2006-2007 } \\
\text { (jul. } 2006 \text { a jul. 2007) }\end{array}$ & $\begin{array}{c}\text { 2007-2008 } \\
\text { (jul. 2007 a ene. 2008) }\end{array}$ \\
\hline Proyectos de ley presentados & 1.460 & 547 \\
\hline Leyes y resoluciones aprobadas & 203 & 104 \\
\hline $\begin{array}{l}\text { Investigaciones de interés político asumidas por la } \\
\text { Comisión de Fiscalización }\end{array}$ & 17 & 15 \\
\hline Invitaciones a ministros y altos funcionarios & 25 & 20 \\
\hline \multicolumn{3}{|l|}{ Proyecto de ley presentados } \\
\hline Grupos Parlamentarios & 1.160 & 385 \\
\hline Poder Ejecutivo & 218 & 115 \\
\hline Organismos Autónomos & 77 & 47 \\
\hline Iniciativas del Parlamento Anterior & 20 & - \\
\hline Total & 1.475 & 547 \\
\hline \multicolumn{3}{|c|}{ Proyectos de ley presentados por Grupos Parlamentarios } \\
\hline APRA & 308 & 113 \\
\hline Nacionalista UPP & 414 & 70 \\
\hline PNP & 34 & 43 \\
\hline Alianza Parlamentaria & 128 & 38 \\
\hline $\mathrm{UN}$ & 115 & 36 \\
\hline Fujimorista & 55 & 18 \\
\hline Grupo Especial Demócrata & 23 & 23 \\
\hline Multipartidario & 83 & 44 \\
\hline Total & 1.160 & 385 \\
\hline \multicolumn{3}{|l|}{ Concurrencia de Ministros } \\
\hline Al Pleno & 70 & 29 \\
\hline A la Comisión Permanente & 3 & 0 \\
\hline A las Comisiones Ordinarias & 175 & 64 \\
\hline A la Presidencia & 15 & 29 \\
\hline Total & 263 & 122 \\
\hline
\end{tabular}

Fuente: Indicadores de gestión. Periodo anual 2007 - 2008. Unidad de estadística de la dirección general parlamentaria. Oficialía Mayor. 


\section{Relación entre los poderes del Estado}

En términos generales, la relación entre el Poder Ejecutivo y el Poder Legislativo transcurre sin mayores sobresaltos; como acabamos de ver, el Poder Ejecutivo ha aprobado más iniciativas en el Congreso que los propios parlamentarios. Pese a no contar con mayoría, el partido de gobierno ha logrado armarla cuando ha sido necesario. Ahora bien, es justo decir que, a pesar de esto, iniciativas controversiales, que implican por ejemplo reformas constitucionales o cambio de leyes orgánicas importantes, cuya aprobación requiere de mayorías calificadas, se ven muy difíciles de lograr en el Congreso, dado su nivel de fragmentación y escasa disciplina en la mayoría de los grupos parlamentarios.

En cuanto a la relación entre el Poder Ejecutivo y el Poder Judicial, ha habido mucha controversia respecto a la autonomía del segundo respecto al primero. En términos generales, ella se ha manifestado en algunas disputas por aumentos de presupuesto; pero una de las "pruebas de fuego" de esta ha sido el tema de la extradición y posterior enjuiciamiento al ex presidente Fujimori. Según algunos analistas, el gobierno necesitaría de los votos fujimoristas en el Congreso; por ello, habría movido influencias en el Poder Judicial para entorpecer el proceso de extradición. Una vez ocurrida esta, según este punto de vista, mérito de la justicia chilena antes que de la peruana, se preveía una suerte de ruptura de relaciones entre el gobierno y el fujimorismo o, en todo caso, una negociación por la cual el gobierno nuevamente movería sus influencias en el Poder Judicial para lograr un trato indulgente con el acusado ex presidente. Lo interesante es que los juicios a Alberto Fujimori se desarrollan con normalidad e imparcialidad, y en el Congreso las relaciones entre el gobierno y el fujimorismo no parecen haber cambiado en absoluto, todo lo cual debilita en extremo la hipótesis de que existiría un acuerdo político entre ambos, así como de una injerencia directa del gobierno sobre el Poder Judicial.

\section{Relación entre los distintos niveles de gobierno}

Como ya hemos visto, lo más importante en cuanto a la relación entre el gobierno central y los gobiernos regionales y locales, ha sido la desactivación del Consejo Nacional de Descentralización (CND) y la creación de la Asamblea de Presidentes Regionales (por iniciativa de ellos mismos) en el mes de marzo. Y como adelantamos, lo que podría haber sido una disputa por recursos presupuestales se ha diluido en medio de los problemas en la ejecución de gastos que han aumentado sustancialmente en los últimos años.

Este problema atraviesa al conjunto de la administración pública. Así, tenemos que el avance de ejecución presupuestal hasta octubre del 2007 en los gobiernos regionales llegaba al 37\%, mientras que lo avanzado en el gobierno central no se alejaba mucho, llegando al 46\%. Tomando en cuenta que el presupuesto de inversión de los gobiernos regionales aumentó de 1.074 millones de soles a 3.843 millones de soles entre 2004 y 2007, mientras que el del gobierno central sólo se incrementó en $41 \%$, la capacidad de gasto de los gobiernos regionales no parece ser muy inferior. Esto pone sobre el tapete la necesidad de emprender una reforma del Estado integral, que tenga como uno de sus objetivos la construcción de capacidades técnicas e institucionales en todos los niveles. 
Cuadro 3: Avance en la ejecución de inversiones en Gobiernos Regionales y Gobierno Central, 2004-2007 (En millones de soles y porcentajes).

\begin{tabular}{lccccccc}
\hline & \multicolumn{3}{c}{ Gobiernos regionales } & & \multicolumn{3}{c}{ Gobierno central } \\
\cline { 2 - 3 } \cline { 6 - 8 } Año & Presupuesto & Ejecución & $\begin{array}{c}\text { Avance de } \\
\text { ejecución }\end{array}$ & & Presupuesto & Ejecución & $\begin{array}{c}\text { Avance de } \\
\text { ejecución }\end{array}$ \\
\hline 2004 & 1.074 & 758 & $72 \%$ & & 3.611 & 2.733 & $76 \%$ \\
2005 & 1.443 & 994 & $69 \%$ & & 4.072 & 3.141 & $77 \%$ \\
2006 & 2.572 & 1.445 & $56 \%$ & & 4.416 & 2.918 & $66 \%$ \\
$2006^{8}$ & 2572 & 961 & $37 \%$ & & 4416 & 2105 & $48 \%$ \\
$2007^{9}$ & 3.843 & 1.412 & $37 \%$ & & 5.116 & 2.333 & $46 \%$ \\
\hline
\end{tabular}

Fuente: Ministerio de Economía y Finanzas. Elaboración: Vigila Perú.

\section{Evaluación general sobre el funcionamiento y calidad de la democracia}

En términos generales, a manera de balance, podría decirse que en el Perú parece estarse configurando una suerte de dinámica "neodualista". De un lado, tenemos un país relativamente estable, con una dinámica firme de crecimiento económico, que da lugar a mayores posibilidades de gasto público, que involucra básicamente a la costa del país. Esta impresión de estabilidad se refuerza al mirar el Perú a la luz tanto de su pasado inmediato como del escenario de la región andina. Sin embargo, hay otro sector del país que demuestra que esta solidez todavía no está consolidada y que podría revertirse. Pese a la estabilidad y el crecimiento, otros sectores se quedan rezagados, no siendo capaces de articularse por sí solos a sectores dinámicos; se trata de los sectores más pobres, más tradicionales.

En este panorama, el gobierno apuesta claramente a estimular la inversión privada para consolidar el crecimiento, desatendiendo relativamente el emprender reformas con énfasis distributivos y sociales; al mismo tiempo, el mayor nivel de recursos fiscales ha desnudado la precariedad del aparato público, que enfrenta dificultades para ejecutar sus presupuestos. Todo esto genera malestar y ha dado lugar a un aumento en la conflictividad social, que sin embargo no remece la esfera política, dado el carácter local y particularista de la mayoría de las reivindicaciones, la debilidad de las organizaciones sociales y de los grupos políticos opositores. Con todo, lo que podría llamarse la distribución territorial y social del descontento ciudadano parece todavía reproducir en términos generales el mapa de las elecciones nacionales de 2006, con lo que el actual crecimiento parece ser todavía vulnerable al desarrollo de propuestas antisistema.

Emprender una reforma del Estado que fortalezca la presencia y la calidad de la intervención del Estado, sus capacidades regulatorias y promotoras, así como un fortalecimiento de las instituciones representativas, requiere cambios que involucran no solamente a las entidades 
nacionales, también a las subnacionales (regionales y locales), que adquieren una mayor importancia en el marco del proceso de descentralización y aumento de presupuestos, lo que los hace visibles ante la opinión pública. Por ahora, lamentablemente, este tipo de preocupaciones ocupa todavía un espacio marginal en el debate público.

\section{REFERENCIAS}

Congreso de la República. 2007. “Indicadores de gestión”. Unidad de estadística de la Dirección General Parlamentaria.

Defensoría del Pueblo, 2007. Conflictos sociales. Reportes mensuales.

García, Alan. 2007. "El síndrome del perro del hortelano". El Comercio, 28 de octubre.

García, Alan. 2007. "Receta para acabar con el perro del hortelano". El Comercio, 25 de noviembre.

Grupo Propuesta Ciudadana. 2006. "Participa Perú" N. 31.15 agosto.

Instituto Nacional de Estadística e Informática. 2007. Encuesta Nacional de Hogares.

Tanaka, Martín. 2007. "Balance del primer año del Congreso". En: Boletín del Consorcio de Investigación Económica y Social (CIES) N. 48.15 agosto.

Tanaka, Martin. 2007. "Ideas para mejorar el funcionamiento del Congreso". Peru21, 14 de agosto.

Martín Tanaka es peruano, Doctor en Ciencia Política y Maestro en Ciencias Sociales por la Facultad Latinoamericana de Ciencias Sociales (FLACSO) sede México; Licenciado en Sociología por la Pontificia Universidad Católica del Perú. Actualmente es Director General del Instituto de Estudios Peruanos y profesor del Departamento de Ciencias Sociales de la Pontificia Universidad Católica del Perú. (E-mail: mtanaka@iep.org.pe)

Sofía Vera es bachiller de sociología en la Universidad Católica del Perú. Trabaja actualmente como asistente de investigación en el Instituto de Estudios Peruanos.

(E-mail: svera@iep.org.pe) 
Cuadro 1: Gabinete al finalizar 2007

\begin{tabular}{|c|c|c|c|}
\hline Ministerio & Nombre & Partido & Inicio de gestión \\
\hline $\begin{array}{l}\text { Presidencia del Consejo de } \\
\text { Ministros }\end{array}$ & Jorge del Castillo & APRA & 28 julio 2006 \\
\hline Defensa & Antero Flórez-Araoz ${ }^{10}$ & PPC & 20 diciembre 2007 \\
\hline Justicia & Rosario Fernández Figueroa ${ }^{11}$ & Independiente & 20 diciembre 2007 \\
\hline Mujer y Desarrollo Social & Susana Pinilla Cisneros ${ }^{12}$ & APRA & 20 diciembre 2007 \\
\hline Salud & Hernán Garrido Leca ${ }^{13}$ & APRA & 20 diciembre 2007 \\
\hline Trabajo & Mario Pasco Cosmópoli14 & Independiente & 20 diciembre 2007 \\
\hline Vivienda y Construcción & Enrique Cornejo Ramírez ${ }^{15}$ & APRA & 20 diciembre 2007 \\
\hline Agricultura & Ismael Benavides Ferreyros ${ }^{16}$ & Independiente & 21 mayo 2007 \\
\hline Interior & Luis Alva Castro ${ }^{17}$ & APRA & 26 febrero 2007 \\
\hline Comercio Exterior y Turismo & Mercedes Aráoz Fernández & Independiente & 28 julio 2006 \\
\hline Economía y Finanzas & Luis Carranza Ugarte & Independiente & 28 julio 2006 \\
\hline Educación & José Antonio Chang Escobedo & Independiente & 28 julio 2006 \\
\hline Energía y Minas & Juan Valdivia Romero & APRA & 28 julio 2006 \\
\hline Producción & Rafael Rey Rey & Renovación Nacional & 28 julio 2006 \\
\hline Relaciones Exteriores & José A. García Belaúnde & Independiente & 28 julio 2006 \\
\hline Transportes y Comunicaciones & Verónica Zavala Lombardi & Independiente & 28 julio 2006 \\
\hline
\end{tabular}

10 Renovación del gabinete ministerial. En reemplazo de Alan Wagner.

11 Renovación del gabinete ministerial. En reemplazo de María Zavala.

12 Renovación del gabinete ministerial. En reemplazo de Virginia Borra.

13 Renovación del gabinete ministerial. En reemplazo de Carlos Vallejos.

14 Renovación del gabinete ministerial. En reemplazo de Susana Pinilla.

15 Renovación del gabinete ministerial. En reemplazo de Garrido Lecca.

16 En reemplazo de Juan José Salazar, quien presentó su renuncia al cargo tras el polémico acuerdo firmado con los cocaleros del Cusco.

17 En reemplazo de Pilar Mazzeti que presento renuncia tras escándalo de la compra sobrevalorada de patrulleros. 


\begin{tabular}{lll}
\hline \multicolumn{1}{c}{ Experiencia } & Nacimiento & Profesión \\
\hline Congresista & 2 julio 1950 & Abogado \\
Representante ante la OEA & 28 febrero 1942 & Abogado \\
$\begin{array}{l}\text { Procuradora de OSINERG } \\
\text { Ex ministra de Trabajo y Promoción del Empleo }\end{array}$ & - & Abogado \\
Ex vicepresidente de Interbank & 31 mayo 1954 & Antropología \\
$\begin{array}{l}\text { Ex presidente del tribunal de ética del Consejo de la Prensa } \\
\text { Peruana }\end{array}$ & 1960 & Administración \\
$\begin{array}{l}\text { Presidente ejecutivo del Banco de la Nación } \\
\text { Presidente de la Asociación de Bancos }\end{array}$ & - & Abogado \\
Congresista & 10 mayo 1945 & Administración \\
Vicepresidenta de INDECOPI & 17 febrero 1942 & Economistamo \\
Ex director BCR & 5 agosto 1961 & Economista \\
Ex rector UNSM & 21 diciembre 1966 & Economista \\
Ex congresista & 19 mayo 1958 & Ing. Industrial \\
Parlamentario andino & 6 febrero 1948 & Arquitecto \\
Asesor de la CAN & 26 febrero 1954 & Ing. Industrial \\
Secretaria de Gestión Pública de PCM & 16 marzo 1948 & Diplomático \\
\hline
\end{tabular}


